\title{
SOBRE UNA PROPUESTA DE LECTURAS DE DIEZ CUENTOS DE HANS CHRISTIAN ANDERSEN
}

\author{
Ronald Campos López \\ Estudiante de la Maestría académica en \\ Literatura Latinoamericana, Universidad de Costa Rica \\ San José, Costa Rica
}

Recibido 9-XII-2008 • Aceptado 12-V-2009 • Corregido 20-V-2009

\begin{abstract}
Resumen: Se presenta una propuesta metodológica de lecturas de diez cuentos de Hans Christian Andersen, aplicable a una situación de aula de estudiantes de quinto grado de la Escuela de San Rafael de Coronado. Dicho enfoque se orienta desde una perspectiva del valor pragmático de la literatura, en donde el niño y la niña se constituyan a sí mismos como lectores-estudiantesindividuos sociales simultáneamente, a medida que ejecutan su capacidad crítico-analítica, abstracta, simbólica, comparativa, lingüística y representativa sobre la discursividad hegemónica de la identidad y en contra de la dogmática función social del abordaje metodológico cotidiano de los textos literarios aún en las aulas costarricenses. Es por ello que resultan imperativos lecturas y análisis (de)constructivos de textos, literarios propiamente en este caso, los cuales problematicen la institucionalidad del lenguaje en los procesos de enseñanza $y$ aprendizaje.
\end{abstract}

Palabras clave: Educación, enseñanza, literatura, orientación para la lectura, Andersen.

\section{Aproximación frente al hecho literario y el lenguaje}

\subsection{Sobre el concepto de literatura}

Se han problematizado los conceptos de literatura desde múltiples perspectivas teóricas desde el último siglo, como respuesta a necesidades de comprender precisamente el grado de representatividad u obcecación de los textos literarios o lo literario. Frente a una convencionalidad ${ }^{1}$ sobre los estudios de la literatura en el nivel pedagógico costarricense, este artículo pretende instaurar una visión pragmática, principalmente desde el análisis del discurso según Van Dijk (1977, citado en García, 1994) y la Teoría empírica de la literatura de Schmidt (1979, citado en García, 1994), como metodología de estudio, enseñanza y aprendizaje. Dicha propuesta se mantiene en diálogo con las propuestas teóricas postestructuralistas de poetólogos como Barthes y Todorov (1963, 1966; y 1970, citados en García, 1994), las cuales toman como foco determinante al lector y la recepción textual, antes 


\begin{abstract}
A methodological reading proposal about ten Hans Christian Andersen's stories is presented, applied on a fifth-grader classroom situation from the San Rafael de Coronado School. This approach is oriented to a perspective of literature pragmatic value, where the child becomes simultaneously social reader-studentindividuals, as the child's critical-analytical, abstract, symbolic, comparative, linguistic and representative skills concerning identity hegemonical discourse are executed; this against the dogmatic social function of the current daily methodological approach for literary text, exclusively in this case. This is why it turns out essential to apply constructive and literary text reading and analysis, which trouble the institutionalism of language during teaching and learning processes.
\end{abstract}

Key words: Education, teaching, literature, reading orientation, Andersen. que la producción o fisonomía del texto, afianzada en sí, ya que el texto literario no corresponde, según Schmidt, a un "absoluto ontológico, portador por sí mismo de un significado y de un valor estable" (1979 citado en García, 1994, p. 261). Al contrario, todo texto equivale a "una serie de iniciativas de atribución de significado y de valor por parte de los receptores, de acuerdo con su propia situación contextual y en virtud del conjunto de convenciones sociales" (Schmidt, 1979 citado en García, 1994, p. 261).

Entretanto, desde un punto de vista meramente pragmático, la literatura es considerada como "un conjunto de marcas culturales del discurso, que permiten identificarlo precisamente como literatura en la pragmática del acto verbal comunicativo" (García, 1994, p. 248), a pesar de la arbitrariedad en los fundamentos de su naturaleza.

\subsection{De la noción de texto literario y su abordaje por parte del lector}

Se ha discutido dificultosamente dónde se encuentra el significado de un texto literario. Ya sea en este último propiamente, ya sea en el lector:

La pragmática propone la situación de todo enunciado lingüístico y en consecuencia la cuestión de su significado en la perspectiva del mismo como acto de habla. El significado es el resultado de un acto comunicativo propuesto y codificado por el emisor y aceptado y descodificado por el receptor (García, 1994, p. 248).

Este es el principio fundante de la Estética de la recepción de Jauss (1977, citado en García, 1984) y su metodología pragmática para la literatura, pues se afirma que: "En el necesario acto comunicativo que crea el significado, el receptor, muy en especial el caso del lector literario, confirma o destituye con su acuerdo y comprensión, o mediante los fenómenos contrarios, la propuesta significativa del productor del texto" (García, 1994, p. 252). 
Si bien es cierto, el lector aborda el texto literario y lee desde una macroestructura (contexto sociocultural e histórico) determinada. La lectura no equivale a un acto desmedido o liberal. La omisión de que el sujeto quien lee concluye un circuito comunicativo del texto, originado en las intenciones productivas del autor, niega los fundamentos textuales del juicio estético y privilegia la literariedad.

Gadamer (1960, citado en García, 1994), por su parte, defiende que el lector percibe del texto sólo aquello relacionado con él mismo. Barthes (1963, citado en García, 1994) sostiene que el autor es quien posibilita estas identificaciones afectivas de los lectores con base en las estrategias discursivas manifiestas en el texto; es decir, los «huecos» que permiten "activar y comprometer la imaginación lectora en la cooperación constructiva [y significativa] del sentido" (Iser, 1972, citado en García, 1994, p. 277). Esta cooperación constructiva del significado no satisface una libertad imaginativa incontrolada e imprevisible por parte del lector, sino dentro de un marco de posibilidades de lectura propiciado por el texto en sí. Aunque este último resulta una estructura consistente: "El intérprete debe distinguir lo que un texto implica de lo que no implica. Debe dar al texto todas sus expectativas, pero manteniendo al tiempo normas y limites" (García, 1994, p. 297), dentro de la validez de la interpretación del significado textual.

Los niños y las niñas poseen su capacidad lectora restricta debido a su formación pedagógico-sociocultural, familiar y neuropsicológica. No obstante, la competencia textual, en efecto, constituye "la capacidad de captar (o atribuir) la coherencia de los textos independientemente de su forma lingüística" (Lozano, 2007, p. 20). En consecuencia, el concepto de competencia textual "puede ser enriquecido con el de competencia intertextual" (Lozano, 2007, p. 21). Eco (citado en García, 1994) denomina este proceso complementario como hipercodificación; en otras palabras, y ejemplificando con hechos del ámbito educativo, tal proceso hipercodificante ocurre durante el análisis de textos cuando el o la estudiante manifiesta su competencia textual y se provee a sí (con ayuda del docente mediador o sin ella) un marco de estrategias y recursos (signos y símbolos), con el fin de que en el proceso de (de)construcción del texto logre reconocer, a fin de cuentas, criterios de coherencia en aquello que lee desde su competencia (inter)textual.

Por tanto, la interpretación generada por un lector $u$ oyente sobre un texto responde a "una operación de tipo pragmático (...) [sobre] el "argumento» de que se habla" (Violi y Manetti, 1979 citados en Lozano, 2007, p. 26). En última instancia, la coherencia pragmática es asignada por el lector. La lectura corresponde siempre a un proceso de inclusión y exclusión de unidades semánticas y discursivas pertinentes a la competencia (inter)textual. De acá la importancia de contar con los conocimientos previos, los sistemas de creencias, realidades y experiencias cotidianas, familiares, amorosas, existenciales, filosóficas, estéticas, entre otras, de los estudiantes al concebir un proceso de decodificación lectora respecto de distintos textos y discursos.

En fin, a pesar del aparente autotelismo y la autonomía del texto, el lector es quien coopera (ya sea adolescente, adulto o niño), con las funciones intratextuales (en el nivel de la forma y coherencia frástica), al ser orientado hacia el principio funcional de los significados textuales, por medio de estrategias discursivas inscritas en el texto mismo.

Sin embargo, ¿desde dónde es el lector capaz de colaborar con su proceso de (de)construcción (con) (d)el texto?

\subsection{Estudiante-lector-sujeto social y el lenguaje: Un asunto de identidad}

El sujeto lector contribuye desde sus posibilidades de lectura y ambigüedad, en tanto él o ella dice o desdice los discursos que 
lo o la configuran. Frente a la experiencia de lectura, no es imperativo ni esperable que el lector lea la quimérica totalidad del texto; es decir, "alcance" la Verdad del texto y, en el peor de los casos, el Sentido del Autor. En ocasiones, confirma Barthes (1963, citado en García, 1994), resulta el mismo texto quien lee al sujeto, puesto que ambos se confabulan cual discursividades o textualidades simultáneas, en una dimensión temporal y espacial en el momento cuando son pronunciados 0 leídos, vividos los discursos, productos de acontecimientos históricos e, indiferentemente, asidos por el lenguaje.

En su Lección inaugural, Barthes (2003) establece que los poderes habitantes en el lenguaje (entendiendo este último como una legislación) determinan todo discurso sostenido en sí mismo, desde un lugar, dentro o fuera, en el poder hegemónico y centralizado de una sociedad. En consecuencia, todo lector, en tanto sujeto, se encuentra sujetado, pues él mismo corresponde al espacio en donde habla siempre otro.

Los sujetos son, por tanto, formaciones discursivas hiladas por el poder y para él, inscrito en el lenguaje. Con lo anterior, se puede decir que la experiencia humana está articulada y organizada por los poderes: la cultura no es sino dentro del lenguaje, como memoria no genética (Rojas, 2008, p. 7).

No es de extrañar, entonces, que la "identidad" de un sujeto resulte un constructo lingüístico. El sujeto lee desde su "propia" identidad interiorizada. De acuerdo con Butler (2001), toda marca de "identidad" es una imagen afianzadora y un instrumento de poder siempre desde el otro. Cabría preguntarse, entretanto:

(...) ¿en qué medida las prácticas reguladoras de la formación y la división de género constituyen la identidad, la coherencia interna del sujeto y, de hecho, la condición de la persona de ser idéntica a sí misma? ¿En qué medida la "identidad" es un ideal normativo más que un rasgo descriptivo de la experiencia? (p. 50).

Por consiguiente, Barthes continúa diciendo en su Lección inaugural: “(...) la lengua, como ejecución de todo lenguaje, no es ni reaccionaria ni progresista, es simplemente fascista, ya que el fascismo no consiste en impedir decir, sino en obligar a decir" (2003, p. 120). Junto a ello, Butler expresa su inmediata e inminente necesidad de problematizar la "identidad" entendida, precisamente, en términos de imposición:

La movilización de las categorías de identidad con miras a la politización siempre sigue estando amenazada por el prospecto de que la identidad se convierta en un instrumento del poder al que nos oponemos. Ése no es motivo para no usar la identidad, y para no ser usados por ella. No hay ninguna posición política purificada de poder, y tal vez sea esa impureza lo que provoca la capacidad de acción como interrupción potencial y cambio total de los regímenes reguladores (p. 25).

No obstante, la posibilidad de problematizar la "identidad" y, por lo tanto, al lenguaje, existe. No así el escapar de este último. Barthes (2003 citado en Rojas, 2008 , p. 9) "entiende la literatura como una forma tramposa de operar (en) el lenguaje, es un engaño que posibilita escuchar a la lengua en un espacio fuera del poder".

Tal fullería de la literatura se organiza alrededor de tres fuerzas: a) la mathesis, en tanto: "El saber que ella [la literatura] moviliza jamás es ni completo ni final; la literatura no dice que sepa algo, sino que sabe de algo" (Barthes, 2003, p. 125); b) la mímesis, de acuerdo con sus funciones representativas y utópicas sobre la realidad; y c) la semiosis, respecto del cómo "actuar los signos en vez de destruirlos" (Rojas, 2008, p. 11) o considerarlos como constructos fijos o ahistóricos.

El papel de la literatura en la enseñanza secundaria y primaria debe ser, precisamente, a partir de estos tres criterios anteriormente expuestos, la promoción de un acto crítico de los regímenes reguladores en la lectura, desde el cual el y la estudiante como sujetos sociales configuren una "identidad" mayormente plurisignificativa y polivalente. La propuesta de análisis y pautas teóricas mencionadas orientan a que la pragmática significativa en torno al texto literario problematice, primero, la actuación y juego de los signos del lenguaje 
y, segundo, "la identidad" del lector, entendida como discursividad verosímil de un discurso hegemónico, el cual homogeneíza las formas de leer y restringe, caducamente, la polisemia textual.

Tal ejercicio (de)constructivo del texto, principalmente literario, implica una inestabilidad permanente del sujeto lector y La Verdad al leer, en tanto rehúya y recupere su lugar instaurado por los poderes del lenguaje; es decir, en la medida en que logre resignificar los procesos de "subjetivación" desde la colectividad (su contexto familiar, sociocultural, histórico e inmediato), dentro del proceso de enseñanza y aprendizaje, desde los procesos de escritura y lectura (ambos indiscutiblemente simultáneos).

\section{Problematización y situación de la literatura ¿infantil? y su ¿puesta en práctica?}

Los procesos operativos excluyen o etiquetan arbitrariamente las prácticas literarias. Por ende, se escucha hablar de literatura latinoamericana, española, erótica, feminista, gay-homoerótica, infantil... Si se formula y enseña la literatura desde estas "etiquetas", se continuará equivocando su categoría de símbolo y de práctica translingüística. Todo texto es simbólico, pues "el símbolo, no es la imagen, es la pluralidad misma de sentidos" (Barthes, 1966 citado en García, 1994, p. 269) y, según Eco, "los símbolos crecen, pero jamás permanecen vacíos" (1990 citado en García, 1994, p. 316).

La literatura "infantil" se ha representado, injustamente, como un espacio de lo didáctico, sencillo, familiar, lúdico, manejable y fácilmente entendible. El hecho de que estas prácticas sean nombradas "infantiles" 2 obedece a una mirada programática, ya hacia el deleite por el juego o la retórica, o ya hacia una formación educativa. Este último criterio ha pesado más en tanto esta literatura es considerada como miscelánea, o bien dogmática, pues "vehiculiza" valores relativos a una ideología hegemónica.
La literatura "infantil" aunada a un proceso de formación pedagógico es mediatizada por padres de familia, docentes, críticos y especialistas teórico-curriculares, así como editores, pues, según Bajour y Carranza (2005), las editoriales organizan estrategias de mercadeo que garantizan no sólo las ventas, sino también la manipulación ideológica del fenómeno de lectura y aprendizaje, mediante esta visión dogmática de la literatura.

Resulta frecuente encontrar tácticas de repetición tales como ilustraciones o soportes explicativos dentro de los libros o composiciones literarios para niños y niñas. Ello responde a los fines especificativos de la Lectura dirigida, propia del proceso de formación identitaria. Habitualmente, se aprueba que la literatura "infantil" recurra al recuerdo, ya que la nostalgia propicia la recuperación u obliga a revisitar la condición pueril o edénica perdida, o bien reafirmar un marco ideológico tradicional propio del "folklore" de una nación, cuya "identidad" (no se pierda de vista la intrínseca relación entre "folklore" e "identidad") o institución discursiva imperante se funda precisamente en esos discursos que rescatan para sí los temibles epítetos de "didáctico" y "moralista" en las prácticas para niños.

Bajour y Carranza (2005) exponen que, en la mayoría de los casos, estas prácticas mediadoras establecen y conservan relaciones asimétricas entre el destinatario y el texto, puesto que los niños y niñas, quienes se pretende lean el texto, no concuerdan con los sujetos cotidianos que asisten a las aulas o se desenvuelven en los espacios de las sociedades posmodernas, sino que más bien equivalen a representaciones de niños y niñas, idealizaciones externas de lectura, las cuales responden indudablemente a marcas discursivas preexistentes y electas adrede, mediante filtros institucionales (padres de familia, maestros, editores, teóricos, entre otros).

Claramente, se observa una subestimación de la literatura mediante el calificativo "infantil". Por medio de ella, se sustentan procesos de formación 
institucionales, los cuales pronuncian todavía más los poderes del lenguaje, de modo que acentúan la manipulación ideológica de los sujetos involucrados por medio de una axiología representativa de la ideología hegemónica. Las prácticas literarias, por tanto, se ven reducidas a una interpretación lectora y escritural, en función del "deber ser"; es decir, la "identidad" inscrita desde la pedagogía, la moral, la política y la religión; todos estos últimos denominados, por Althusser (1977), Aparatos Ideológicos del Estado.

Resulta imperativa, entonces, la problematización inmediata de esta función socializadora de la literatura "infantil", desde y para ella misma, pues, como literatura, debe cuestionar las marcas ideológicas y ahistóricas que inmovilizan la plurisignificación del signo lingüístico, tendiéndoles trampas, precisamente, a los actos verosímiles de lectura y escritura hegemónicas. Sólo a partir de este diálogo (en términos de dialéctica, de conflicto discursivo, antes que conciliador), el y la estudiante-sujeto-lector y lectora se movilizará dentro de su lugar establecido por los poderes del lenguaje y asumirá la lectura y escritura en función de una institución política e ideológica histórica.

\section{Propuesta de lecturas}

\subsection{Sobre el corpus de trabajo}

Posterior a la lectura de un corpus de diez cuentos de H. C. Andersen, y de acuerdo con las aproximaciones teóricas anteriormente expuestas, se plantea una estrategia de motivación y generación de los procesos de competencia (inter)textual en un sector específico de niños. El corpus textual se sustenta en los cuentos: "Historias del Sol", "Holger el danés", "Ib y Cristinita", "Juan el Bobo", "La aguja de zurcir", "La campana", "La casa vieja", "La dríade", "La espinosa senda del honor" y "La familia de Hühnergrete".

La escogencia de estos textos ha sido aleatoria, desde el número 70 hasta el 79 de la serie disponible en la Biblioteca Digital Ciudad Seva, con el fin de no manifestar algún filtro subjetivo en relación con la pluralidad estético-ideológica de los textos.

Se encuentran distintos motivos en esta selección de cuentos, los cuales pueden agruparse de acuerdo con criterios temáticos que, a su vez, permitirían diferentes técnicas y recursos durante su proceso efectivo de lecturas, las cuales deberán permitir un enfoque significativo y crítico, subvirtiendo y polemizando los poderes del discurso hegemónico en todo momento.

Estos textos abren la posibilidad de establecer contacto con los ejes transversales propuestos por el Ministerio de Educación Pública (M.E.P.) de Costa Rica ${ }^{3}$, en tanto las descripciones y (re)creaciones pictóricas propuestas se vinculan con la visión del espacio físico y ecológico de los niños y niñas; análisis de conductas y vivencias implicadas en el desarrollo de la sexualidad (entiéndase en el amplio sentido del comportamiento y vivencias humanas); y las relaciones ético-sociológicas entre el sujeto-lector-ciudadano y los Aparatos Ideológicos del Estado.

\subsection{El corpus y los lineamientos sobre la enseñanza de la Lengua Materna según el Ministerio de Educación Pública}

De acuerdo con el Plan de Estudios de Español de I y II ciclo del M.E.P., los enfoques humanista, racionalista y constructivista de la Política Educativa hacia el Siglo XXI demandan que el programa de enseñanza y aprendizaje de la Lengua Materna se dirija principalmente al desarrollo de potencialidades de pensamiento y competencias comunicativas, mediante la estimulación lingüística y el razonamiento de la comprensión e interpretación. A pesar de dichos enfoques, se contemplan fuertemente todavía criterios estilísticos, formalistas y dogmáticos, los cuales restringen la comprensión del hecho literario, tanto en 
primaria como en secundaria, respecto de la lectura y el abordaje teórico literarios.

En el caso de primaria, se insiste todavía en hablar de una literatura "infantil", enfatizada por el propio programa de estudios, en términos de "un acercamiento temprano y placentero a este tipo de textos, para que los niños disfruten, interpreten y evalúen las lecturas realizadas y se conviertan en lectores independientes" (Costa Rica, M.E.P., 2000, p. 23) ${ }^{4}$.

Esta terminología del "placer" y el "disfrute" fácilmente se presta a confusiones operatorias. Barthes (2003) diferenció entre el placer y el goce del texto, en donde el primero se encuentra vinculado con La Lectura de la obra, como rastreo de los indicios o propósitos absolutos del Autor, inscritos en un conjunto material, cerrado y acabado; mientras el segundo se refiere, más bien, al ejercicio insatisfactorio, donde el y la estudiante socavan su arsenal de posibilidades y comodidad frente a una textualidad abierta, en tanto espacio multidiscursivo, para acceder a un panorama más amplio y plurivalente de interpretaciones.

A pesar de los esfuerzos pragmáticos por motivar a los y las estudiantes en los actos de lecturas, hay quienes piensan en una literatura "infantil", denominándola como "educadora de la imaginación del niño por la actividad mental y el proceso imaginativo, en que se involucra el alumno cuando lee o escucha un cuento" (Costa Rica, M.E.P., 2000, p. 23). Dicha perspectiva es altamente insistente:

Sugerimos el empleo de una metodología que logre estimular el amor por el conocimiento, la creatividad, la criticidad y la apreciación por lo estético y lo moral de nuestra cultura. (...) La literatura provee a los niños de disfrute, gozo y entretenimiento (Costa Rica, M.E.P., 2000, p. 15 y 23).

Tales aseveraciones se contradicen teórico-pragmáticamente en sí mismas. Ante todo, el docente debe recordar que su función radica en la orientación hacia múltiples posibilidades de lecturas críticas partiendo y superando simultáneamente las estructuras axiológicas y filtros filosóficos del Estado, pretendidos en los programas de estudios. A pesar de las acciones pedagógicas de aprestamiento del docente, se deben considerar los procesos de «enseñar a leer», como requisito necesario para la construcción de significados desde el registro lingüístico y la abstracción; no obstante, una vez que el niño y la niña se ubican en un nivel superior, el docente debe superar esta riesgosa tendencia de «enseñar a leer», pues enmascara la función homogeneizante de La lectura, de la cual es partidaria la Escuela ideológicamente.

Entretanto, rescato los siguientes beneficios y competencias señalados sobre la enseñanza de la literatura, en el Plan de Estudios de Español de I y II ciclos:

\footnotetext{
- Valorada en sí misma, despojada de la función de servicio ${ }^{5}$.

- Germen de fantasía, de humor $^{6}$, de invención.

- Enriquecimiento de la imaginación y de la sensibilidad.

- Entrenamiento constante en un manejo flexible, complejo, crítico y creativo del lenguaje.

- Orientada hacia la obtención de satisfacciones intelectuales y estéticas.

- Incorporada por medio de la lectura recreativa.

- Promotora de las capacidades de lectura del niño (Costa Rica, M.E.P., 2000, p. 24).
}

\subsection{Destinatarios de la propuesta}

El plan didáctico consiste en proponer un rincón de lecturas con dos sesiones para niños y niñas de quinto grado, cuyas edades oscilan entre los 9 y 10 años. Se toma como sección experimental uno de los grupos de la Escuela de San Rafael de Coronado. Esta población estudiantil presenta características respecto de su conducta y disposición por el aprendizaje y la enseñanza favorables para la dinámica, pues, por lo general, son participativos, respetuosos, colaboradores y atentos durante las lecciones, más cuando existe algún tipo de motivación significativa, particular y llamativa como lo es: Un rincón de lecturas.

La institución se ubica en una región dedicada a la agricultura y ganadería lechera 
en el sector este del cantón de Coronado. La condición socioeconómica promedio de los habitantes de la zona obedece a una clase media, cuyos ingresos salariales les permite un estilo de vida con acceso a medios de comunicación, transporte, aparatos tecnológicos básicos (televisor, equipos de sonido, radiograbadoras, reproductores de discos compactos o video casetes y, en algunos casos, computadoras). Los estudiantes manifiestan un perfil psicopedagógico variado, lo cual permitiría distintas lecturas, de acuerdo con las realidades cotidianas, psicológicas y visiones de mundo de cada uno de ellos. Esto contribuiría con los procesos dialógicos (inter)textuales exitosos.

De acuerdo con las pretensiones curriculares del M.E.P., descritas para un o una estudiante de quinto grado, esta propuesta de lecturas parte de las siguientes capacidades (Costa Rica, M.E.P., 2000, p. 29):

1) Aplicar los conceptos relativos al proceso comunicativo, para establecer una comunicación eficaz en el entorno sociocultural correspondiente

2) Fortalecer conocimientos, habilidades y destrezas en la lectura y escritura

3) Utilizar tipos de lenguaje cotidiano, oral, icónico y literario, según las diferentes situaciones comunicativas

4) Enriquecer el léxico junto con el significado de las palabras

5) Utilizar adecuadamente textos de consulta (el diccionario, las guías telefónicas, las guías de correo electrónico, el libro, el periódico y la revista, entre otros)

6) Reconocer oraciones como unidades del discurso

7) Producir descripciones orales y escritas, según las normas idiomáticas

8) Comprender y relatar experiencias personales, anécdotas, fábulas, leyendas y cuentos, atendiendo a los elementos básicos de la narración y a las normas del idioma

9) Recrear relatos cortos de acuerdo con las posibilidades del estudiantado

10) Interpretar y crear diálogos de obras teatrales, de acuerdo con las características de los o las estudiantes y las normas idiomáticas

11) Comprender y recitar textos poéticos, así como crearlos, según las particularidades de esta manifestación expresiva
12) Incentivar el gusto por la lectura de textos literarios y no literarios

13) Desarrollar habilidades de expresión oral, con miras al perfeccionamiento del discurso.

\subsection{Un rincón de lecturas}

El objetivo de dicha propuesta es generar un espacio de lecturas dentro de la misma aula, destinado a la recreación, ludismo y diálogo (inter)textuales, entre los mismos estudiantes, el docente y, eventualmente, otros sujetos relacionados directa o indirectamente con el proceso de enseñanza y aprendizaje.

La idea del "rincón de lectura" no es novedosa y su aplicación metodológica en el proceso de enseñanza y aprendizaje de educación primaria es irregular o nula, en la mayoría de las aulas. Sin embargo, su orientación teórico-pragmática varía en este caso, pues tradicionalmente se ha concebido tal espacio como un ámbito donde el docente lee a sus estudiantes, o entre ellos mismos, y evalúan la lectura en los niveles literal y organizacional de la información explícita ${ }^{7}$.

En tal caso, dicho "rincón" debe ser acondicionado con una alfombra abarcadora de un área lo suficientemente amplia como para albergar a la totalidad de los niños y niñas. Deberá contar con un mueble al estilo de una pequeña biblioteca o estantes aptos para contener los libros, periódicos, láminas, revistas necesarios; recipientes con lápices, marcadores o crayones de colores, un pote de confites (posibles recompensas o incentivos); así como diccionarios, almohadones, hojas "bond" de colores, reglas, goma y tijeras; mapas tanto de Europa, América y Costa Rica; materiales reutilizables o reciclables, radiograbadora y otros accesorios por incluir durante el proceso; una repisa especial para guardar los títeres, el batón y la silla del docente. La idea general es visualizar un ambiente acogedor (señuelo impresionista para el proceso de lectura y escritura), en donde el niño o la niña se entusiasme, 
relaje y propicie un sitio de expresión. Eventualmente, se puede contar con música instrumental de fondo (con un volumen no distorsionante), en especial durante las actividades de (re)creación. Utilizar la música de fondo durante el período de lectura en voz alta y diálogo con los y las estudiantes queda al criterio del docente. Lo importante es utilizar los recursos y el espacio del aula (García, Campos, Campos y Rojas, 1992).

Se programan dos sesiones, de duración relativa, para la lectura del corpus seleccionado. En cada lapso, el docente se viste con un batón de color vino e interactúa con dos personajes más: dos títeres, un niño y una niña, con quienes establece un diálogo a partir de temáticas cotidianas o pertinentes a las realidades de los habitantes del distrito de San Rafael. Sin embargo, estos temas deben incluir o interconectarse estratégicamente con los distintos cuentos por leer. El docente, por tanto, debe investigar sobre el modus vivendi, acontecimientos o experiencias sociales recientes en la zona, así como los principales móviles socioculturales de los estudiantes y sus familias en general, para posteriormente redactar un guión primario, el cual funcionará como base y esquema del diálogo, de manera que los nudos temáticos, intertextuales, recreativos y significativos se encuentren articulados. Por último, debe confeccionar los títeres y proveerse del vestuario pertinente.

Como se trata de un acto escénico intencionado en todo momento, el docente como expositor debe cuidar aspectos de elocución: el dominio corporal y la gestualidad apoyada en las manos, los brazos, su rostro, la mirada global sobre los oyentes; el hecho de si estará sentado o decidirá levantarse o permanecer en pie un tiempo determinado, o inclusive desplazarse hacia algún punto específico o azaroso. La composición del espacio y el hecho dialógico debe diseñarse de acuerdo con recursos enfáticos, simbólicos, adjuntivos e implicativos, así como de percepción y presentación de una mirada ideológicamente problematizadora y dirigida. Respecto de la dicción, considérense la proyección adecuada de la voz, de modo que no aturda ni fuerce a los y las estudiantes a entender lo dicho; jugar con inflexiones, puesto que estas captan y dirigen la atención sobre el discurso; así como una articulación contribuyente de la recepción de los fonemas y su asociación respectiva con cada uno de los gestos y movimientos articulatorios del aparato fonador. La ausencia de muletillas, al igual que una espontaneidad y destreza improvisadora, le permitirán al docente dominar el contexto discursivo, a los oyentes y a sí mismo, en relación con la claridad, coherencia y organización de las ideas.

Inicialmente, el profesor y los títeres conversan sobre la magia del lenguaje y la poesía, de su presencia cotidiana a su alrededor y su maravilloso misterio. Es pertinente interrogar a los estudiantes, mediante el método clínico (Piaget, 1989), sobre su concepto sobre la poesía y su percepción del mundo. Eventualmente, se le solicita a un voluntario que escriba en una pequeña pizarra portátil, ubicada al lado del espacio de lectura, las opiniones de sus compañeros. Tal ejercicio introductorio permite la discusión y la lectura interactivas de tres cuentos en específico; más que lectura, una adaptación dialógica entre los tres personajes antes mencionados (el docente y los dos títeres) y, paulatinamente, los espectadores. Los textos: "Historias del Sol", "La campana" y "La casa vieja", por su carácter metafórico y sus personajes prosopopeyizados, giran en torno de una realidad cotidiana de lo real maravilloso en la dinámica de los niños y niñas, pero además cargados de un alto simbolismo y apelación a la concepción de la escritura y la vida como un arte viviente y natural (tramposo frente a una visión centralizadora y verosímil), enriquecedores del bagaje (inter)textual de los participantes. Como técnicas de la función fática del lenguaje, pueden integrarse preguntas de suspenso y apelación directa: "¡Y no! ¿Qué creen que pasó...?”, "¡Mmm, no; pero ya no interesa...!”, 
“QQuieren que siga contando lo que pasó?”, "Y había u... había un... ¿había? ¿Qué era...?”, entre otras espontáneas y particulares del sujeto narrante. Es oportuno, en estos casos, que los estudiantes sean provocados para recrear, por medio de dibujos, aquellos paisajes, situaciones o personajes más llamativos para cada uno en relación con las historias recitadas. Puede cerrarse esta actividad con la confección de un mural en la pared con todas las pintoretas de los estudiantes y la autoapreciación artísticocrítica del grupo sobre su trabajo.

Las pintoretas corresponden a un neologismo personal, principalmente, para expresar la necesidad de fusionar u orientar el diálogo entre el texto escuchado y el texto representado pictórica o figurativamente por los y las estudiantes, de acuerdo con sus capacidades de abstracción, correlacionales y motoras.

Una lectura más fluida del cuento "Juan el Bobo" permite no sólo ejemplificar una parodia de la oficialidad intelectual, social y política (mundo de los "adultos" desde un punto de vista arquetípico y hegemónico, si se mantiene la imprecisa e inapropiada concepción de "lo infantil"), para dar cabida al ámbito de lo cómico-lúdico, mediante el arquetipo del "arlequín" (aquel quien es capaz de vacilar, cuestionar y ridiculizar la oficialidad del discurso, desde su lugar permitido por los poderes del lenguaje), representado por el niño. Se incita a que uno o varios de los o las estudiantes con destrezas histriónicas más notorias posicionen en el papel de Juan, con respecto a sus "otros hermanos" y la "corte" (el resto del grupo), y generen cortas escenas en donde rebajen o desestabilicen imágenes de autoridad cercanas: por qué no la del docente mismo, el director o directora de la institución, o sacerdote de la comunidad.

De ser posible, solicíteseles a los y las estudiantes ejecutar la (de)construcción de hechos, experiencias o historias personales relacionadas con el texto, pero esta vez cambiando algunos detalles de los acontecimientos y los nombres de los personajes involucrados, con el fin de transportar su lectura a su inmediatez simbólico-cognitiva, a partir de situaciones de rebajamiento, graciosas o tragicómicas vividas por ellos mismos. Gratifíquense las participaciones y logros de los pequeños actores. Dense, asimismo, sugerencias para su desenvolvimiento eficaz durante una disertación.

Por otra parte, el texto "Ib y Cristinita" permite una relectura a la luz de los grandes esfuerzos, la perseverancia y la recompensa de la vida; pero, además, admite el cuestionamiento de las predicaciones y móviles en torno a la figura masculina ("Ib") y femenina (“Cristinita") principales del texto, en tanto estereotipos de una sociedad patriarcal. Una doble lectura simultánea (de)constructiva de estos valores y patrones sociales dinamiza aún más la lectura y el diálogo (inter)textual durante el proceso.

Obsérvense pasajes como:

Dijo que iba a regalarlos a Cristinita, la hija de un marinero, una niña tan delicada y encantadora, que habría podido pasar por una princesa. Vestida adecuadamente, nadie hubiera imaginado que procedia de una casa de turba del erial de Seis (Andersen, 2005, ๆ 5).

(...) pero luego Cristina se cayó y se echó a llorar; Ib acudió a ayudarla (Andersen, 2005, ๆ 12).

Sin embargo, al separarse vio bien claro en el alma que Cristina debia ser su esposa; ya de niños los habían llamado los novios; le pareció que eran prometidos, a pesar de que ni uno ni otro habían pronunciado la promesa (Andersen, 2005, ๆ 51).

En estas últimas tres citas, se lee al mismo tiempo cómo se reproducen las características de la feminidad, en tanto la mujer "debe ser" débil y bella físicamente, sensible y emotiva, esposa y madre de una familia por medio de la institución matrimonial. Sin embargo, en cada cita, se ataca a este canon, pues aquella "princesa" vive en condiciones paupérrimas; aquel niño abandona su posición de insensibilidad y siente empatía por el otro, así como también vacila y cuestiona el discurso hegemónico social sobre uno de los 
sacramentos de la Iglesia. Ib a lo largo del texto se enfrenta a esta fuerza dicotómica:

Ib escribió, sólo que no encontraba las palabras a propósito, por lo que rasgó muchas hojas; pero al día siguiente había conseguido, redactar la carta dirigida a la muchacha: «He leído la carta que escribiste a tu padre, y por ella veo que las cosas te van espléndidamente y que puedes esperar todavía otras mejores. Pregunta a tu propio corazón, Cristina, y reflexiona en lo que te espera si te casas conmigo. Muy poco es lo que puedo ofrecerte. No pienses en mi ni en lo que de mí haya de ser, piensa sólo en tu felicidad. No estás ligada a mí por ninguna promesa, y si acaso me la diste en tu corazón, te desligo de ella. Que toda la ventura del mundo acuda a ti, Cristinita. Dios sabrá encontrar consuelo para mi corazón. Para siempre tu sincero amigo Ib» (Andersen, 2005, ๆ 61).

(...) los negocios impedían al novio emprender el largo viaje hasta Jutlandia (Andersen, 2005, ๆ 63)

Ib, en este último fragmento, reproduce la demanda social sobre el hombre en tanto proveedor; pues la felicidad y la estructura estable del matrimonio dependen del cumplimiento con dicha tarea. Él no se siente preparado: No puede cumplir. Por tanto, es necesario que ella, programada para vivir y resolver trabajos de casa, consiga a un hombre quien la provea. No obstante, Ib, sin darse cuenta, o tal vez sí, se muestra como un hombre sensible, "sincero", apela a sus propias emociones, a pesar de que la sociedad patriarcal ha dictaminado el silencio y la insensibilidad para el "hombre".

Ib también resulta un héroe, desde el punto de vista de los arquetipos míticos, pues él se enfrenta a grandes pruebas por causa del determinismo y la rivalidad, para al final protagonizar un desenlace triunfante.

Entre tanto, la lectura de este cuento es plurisignificativa y su discurrir depende del manejo dialógico del docente con los y las estudiantes. Al final, se alcanza una trasgresión de los valores patriarcales, la superación de condiciones adversas del héroe por causas o móviles externos a su condición humana; así como un desenlace imprevisible, pues la protagonista muere en condiciones similares a las de su infancia, mientras $\mathrm{Ib}$ estructura un ambiente de bienestar, donde termina asumiendo roles de padre-madre en un espacio exclusivamente "privilegiado" para la mujer: el hogar.

Aunque las fuerzas ideológicas confluyen en este texto, precisamente en la lucha por habitar y engañar los poderes del lenguaje y el discurso dominante, los personajes son muestra de la visión crítica no sólo sobre el proceso de lectura y escritura, sino también sobre aquella demandada función social de la literatura.

Cristina rompió a llorar e Ib hizo lo mismo, y cuando hubieron llorado por espacio de una hora, se tumbaron sobre las hojas y se quedaron dormidos (Andersen, 2005, ๆ 12).

El niño tuvo que ir a la escuela de confirmandos, y el párroco vivía lejos. Por aquellos días se presentó el barquero y dijo a los padres de Ib que Cristina debía marcharse de casa, a ganarse el pan. Había tenido la suerte de caer en buenas manos, es decir, de $\boldsymbol{i r} \boldsymbol{a}$ servir a la casa de personas excelentes, que eran los ricos fondistas de la comarca de Herning. Entraría en la casa para ayudar a la dueña, y si se portaba bien, seguiría con ellos una vez recibida la confirmación (Andersen, 2005, ๆ 34).

Estaba sentada en las rodillas de $\mathbf{I} b$, que era para ella padre y madre a la vez-aquellos padres que habian desaparecido como se esfuma el sueño para niños y mayores. Ib vivía en la casita linda y bien cuidada, en desahogada posición; la madre de la chiquilla yacía en el cementerio de los pobres de la ciudad de Copenhague (Andersen, 2005, ๆ 81).

Por tanto, el análisis de estos fragmentos ejemplifica un esfuerzo por alcanzar lecturas polisémicas y significativas a partir del y con el (con)texto, igualmente válidas y necesarias dentro del proceso de enseñanza y aprendizaje actuales, como en el caso de que los y las estudiantes problematicen y reasuman los roles tanto de la sexualidad masculina como femenina, en medio de las realidades posmodernas y las exigencias sociales, personales, psicológicas y políticas inmediatas a ellos.

Durante la segunda sesión, los textos restantes apuntan mayormente 
hacia lecturas subversivas o críticas respecto de los valores y ejes transversales recomendados por el Plan de Estudios del M.E.P. La sesión podría iniciar de igual manera que la anterior, promoviendo una invitación a la lectura, ya sea con ayuda de una reflexión, un poema, o bien una danza o una canción, que disponga a los niños, niñas y profesor a revisitar el rincón de lecturas. El docente, vestido con su batón, invita a sus otros dos compañeros de cuento (los títeres); pero, además, en esta ocasión, para sorpresa de los niños y niñas, se incorpora un nuevo personaje: un abuelo cuentacuentos, quien bien podría ser un adulto mayor del pueblo, otro docente colaborador o una persona inmersa en el proceso de enseñanza y aprendizaje de los y las estudiantes. Vestido apropiadamente, este personaje encarna la figura arquetípica del anciano narrador de las tradiciones orales y viene, asimismo, a problematizar la figura del "niño aprendiz".

Luego de una familiarización de los niños y niñas con este personaje, con ayuda de recursos o técnicas libres de escoger (dinámicas de ejercitación, relajación, recitación, preguntas personalizadas, entre otras), se inicia en esta oportunidad con la lectura de "Holger el danés". Dicho texto retoma la figura de un héroe nacional y la tradición popular danesa. Se recomienda que la persona quien encarne la figura del abuelo cuentacuentos conozca el texto previamente y sea él quien genere una ambientalidad en torno a las figuras heroicas: ¿Qué es un héroe? ¿Cuáles son sus funciones? ¿Cuáles son sus características y principales atributos? ¿Cómo ayuda o qué hace un héroe por los demás?, entre otras.

Pártase de la figura heroica costarricense por excelencia: Juan Santamaría.

Desde este enmarcamiento, dispóngase una comparación entre Holger y Juan Santamaría en tanto símbolos oficiales de una nación. Es recomendable, de igual manera, contar con un mapamundi y físico de Dinamarca en la biblioteca del rincón, pues son útiles en la medida que los y las estudiantes ubiquen, en el espacio, el ambiente narrativo y conozcan no sólo la trascendencia temporal, sino también espacial del texto en relación con Costa Rica. Tal ejercicio agrega dinamismo al proceso. La referencia de puntos geográficos en el mapamundi debe proporcionar en todo momento algún grado de referencialidad a la historia narrada, pero nunca una ubicación o valoración del autor como ente autentificador del sentido del texto, práctica que socavaría la dinámica de lecturas y retornaría a la creencia sobre La Verdad del Autor frente al texto.

Posterior a la lectura, se pretende que los niños y las niñas sean capaces de establecer comparaciones entre ambos héroes inicialmente, así como determinar la importancia de ellos en la historia de cada una de las naciones. Acto seguido, el abuelo cuentacuentos les lanza la pregunta: “Pero por qué y para qué son realmente importantes los héroes de una nación?” Esta permitirá intensificar la discusión. Interpólense otras interrogantes: “Cuáles héroes de la televisión conocen ustedes?”, “Cómo son ellos?”, “Cuáles son sus trajes?”, “Cómo actúan?", “Cuenta alguno con "superpoderes»?", entre otras.

El objetivo de estas y otras preguntas radica en confrontar la figura hegemónica de "héroe nacional" con la noción de los niños y las niñas sobre este concepto y permitir una lectura más lúdica y crítica sobre el deber ser y propósito de ser de estas figuras. El docente y el abuelo repartirán bocetos a los y las estudiantes. La figura del papel será los contornos de la típica imagen de la estatua de Juan Santamaría (armado y en pos de guerra). Se les pedirá a los y las estudiantes que coloreen dicha silueta, pero ojalá utilizando rasgos característicos de los otros héroes que ellos están acostumbrados a ver en televisión o tiras cómicas, por ejemplo.

Se pretende alcanzar, en la medida de lo posible, una fusión de los rasgos caricaturescos de los héroes de los juegos, series televisivas o revistas de los niños y niñas, y 
la figura emblemática nacional, con el fin de (de)construir tal arquetipo, o más bien leerlo desde otra perspectiva incipiente y dinámica, buscando en todo momento analizar en qué benefician, y por qué, figuras como estas a la "definición" de "la identidad nacional" de Costa Rica, u otro país, por ejemplo; ¿de qué manera me afecta a mí como estudiante y costarricense el contar con una figura "heroica" en mi comunidad, país y escuela en este momento histórico?

Mientras se colorean las imágenes, el abuelo cuentacuentos tensa un tendedero a un costado del rincón de lecturas. En él, cada estudiante debe prensar su (re)creación, después de haber mostrado al grupo su lámina. Una vez todas listas, la atención se direcciona al planteamiento, discusión y síntesis orales de los y las estudiantes sobre las anteriores preguntas sugeridas. El profesor debe redactar un arsenal de interrogantes simples, adecuadas a sus estudiantes, pero congruentes con los propósitos deseados, con el fin de que el diálogo sea productivo.

Del mismo modo, se procede con la lectura interactiva de los textos "La aguja de zurcir" y "La familia de Hühnergrete". Habiendo identificado en ellos valores y conductas "aceptables" o "inaceptables", se le pedirá a algún o alguna estudiante voluntaria que los anoten en la pizarra portátil del rincón, para posteriormente cuestionarlos. Se analizan las consecuencias de la altanería, la superficialidad material y física, la mentira, el narcisismo y el sentimiento de superioridad, entre otros; "vicios" que "deberían ser" exclusos de un proyecto ético-social.

Se conforman grupos. A cada uno el docente entregará las piezas de un rompecabezas. Al armarlo, los y las estudiantes descubren una breve noticia periodística acompañada de una imagen sobre problemas sociales frecuentes en la sociedad: robos, ataques a mano armada, homicidios, drogadicción, maltrato o discriminación contra las mujeres; abuso infantil o contra ancianos, discapacitados, inmigrantes, homosexuales; violencia en las carreteras, escuelas, estadios, hogares, entre otros. En sí, imágenes que le permita a cada grupo relacionar la ausencia o presencia de estos "valores" y "antivalores" (dicha visión manierista debe problematizarse y ser manejada con cautela durante las actividades, con el fin de no caer en ella en algún momento) escritos en la pizarra con las situaciones cotidianas ejemplificadas, así como también la búsqueda de posibles soluciones.

El docente y el abuelo cuentacuentos se apoyan mutuamente en el trabajo de dirigir y ayudar a los equipos de trabajo en el desarrollo de los objetivos de esta actividad. Al final, un o una representante por grupo da a conocer el punto de vista de sus compañeros y compañeras. El profesor anota en la pizarra la idea principal de cada grupo. Se observan luego las convergencias o divergencias en relación con todos los aportes grupales. El docente se encarga de retomar todos los criterios y construir dos o tres oraciones sintéticas de toda la discusión. Trae al rincón cartulinas de distintos colores, marcadores, tijeras y otros, con el fin de que los mismos estudiantes escriban dichas oraciones a modo de llamativos mensajes, que serán colgados en la pared mayormente visible y cercana al espacio de lecturas, junto con los rompecabezas fijamente armados.

Posterior a un breve descanso o gratificación para los y las estudiantes, el docente pega, en un espacio adjunto a estas últimas frases y rompecabezas, el montaje en cartulina de dos guarias moradas de cinco pétalos. Pide a dos estudiantes voluntarios pasar al frente, para que escriban, en el centro de cada flor, las frases coloquiales costarricenses: “¡Pura vida!” y “iTodo bien!", respectivamente. Juntos, profesor y estudiantes tratan de precisar los significados de fondo de estas frases. A medida que se identifica asertivamente una palabra o un significado sobre cada una de ellas, se le pide al o la estudiante pase y escriba este en uno de los pétalos, según corresponda; así hasta agotar los pétalos. Al final, se leen todos y se verifica su pertinencia. 
Se entablan, a continuación, relaciones entre las noticias y situaciones sociales de los rompecabezas y estas frases populares costarricenses. De esta manera, se participa de una visión más crítica del lenguaje y su pragmática social, pues estas frases de uso tan común en el medio nacional, e inclusive en el léxico de estos niños y niñas, funcionan, precisamente, como máscaras para encubrir las carencias y problemáticas sociales del país, sin importar la época o sector sociocultural o geográfico de los hablantes. La idea radica en que los y las estudiantes analicen qué están diciendo cuando pronuncian estas frases y si existe razón de ello, aunque sus realidades inmediatas sean otras muy distintas.

A partir de los resultados de esta dinámica, se les plantea otra pregunta fundamental: “¿Cuáles son nuestros símbolos patrios?" Un voluntario o voluntaria los enlista en la mitad de la pizarra portátil del rincón. Frente a sus respuestas y comentarios, se interroga: "¿Y cuáles son algunos símbolos, marcas y figuras "importantes" para nosotros, pero procedentes de otros países?" Tales respuestas también deben escribirse, en la otra mitad de la pizarra.

Con los resultados obtenidos, se orienta a una discusión (más que maniquea, considerando lo nacional como lo bueno y lo extranjero como lo malo) conciliadora entre estos valores y aquellos otros, como un sólo conjunto válido en la cotidianidad de los estudiantes. Se parte, entonces, desde acá para la lectura de fragmentos de "La dríade" y "La espinosa senda del honor", cuyos núcleos de significado sean comunes y afines a este enmarcamiento temático anterior.

Se rescatan valores y símbolos cosmopolitas, tomando como Estado modélico a Francia, pues este aparece como punto de referencia en ambos textos, o bien Estados Unidos en la dinámica capitalista e ideológica contemporánea, en tanto se los considere proveedores de símbolos hegemónicos e ideológicos fundantes de un imaginario colectivo ideal (utópico). Estos símbolos y valores se anotan en papeles "bond" de colores y se forman con ellos una pirámide, sin importar el orden de los segmentos, en la otra pared del rincón.

La idea no es proponer un modelo ideológico, sino evidenciar una heterogeneidad de valores social posmoderna, cada vez más notoria a partir de los movimientos migratorios y culturales de la globalización y los asentamientos identitarios diversos, no sólo presentes en su comunidad o el cantón de Coronado, sino también en Costa Rica o las imágenes del mundo percibidas por ellos, mediante los medios de comunicación y experiencias personales.

Con la mayor cantidad de materiales de reciclaje a la mano de los y las estudiantes, se propone la confección de un libro-álbum. Bajour y Carranza (2005) comprenden el libro-álbum como un género innovador en cuanto a la lectura de textos literarios, el cual constituye un espacio de (re)creación textual por medio de imágenes confeccionadas a partir de materiales, texturas y superficies diversos, en donde los niños y niñas incorporen corrientes estéticas de las artes plásticas, historietas, diseño gráfico, entre otros; así como fotografías, recortes, fragmentos de textos, versificaciones preescritas o esporádicas suyas durante el proceso dinámico de esta propuesta. En fin, todos los recursos posibles que: 1) permitan actuar a la parodia y el humor absurdo como mecanismos descentralizadores de toda marca fosilizada de lectura sobre literatura "infantil", 2) desarmen las estructuras narrativas convencionales, 3) desmitifiquen la imagen del niño y la niña y la relación de estos con la tradición, 4) al tiempo que propicien el juego (inter)textual y la propuesta de nuevas lecturas. Estas imágenes utilizables o por confeccionar, antes que verosímiles realistas, acordes con la lectura referencial del texto, deben obedecer a una deconstrucción discursiva gráfica y significativa, en la medida de lo posible.

En esta oportunidad, cada niño debe sintetizar un resultado artístico sobre las lecturas realizadas durante las dos 
sesiones. El docente puede motivarlos para que incluyan los dibujos realizados durante las dinámicas, rompecabezas $\mathrm{u}$ otros. Asimismo, que generen al menos un dibujo con crayolas, témperas y sobre la técnica del puntillismo, o bien un "collage", sobre su percepción de la comunidad o sociedad en donde viven. El docente puede brindar algunos ejemplos previamente elaborados o conseguidos, con fines meramente ilustrativos, nunca reproductivos, pues esto restringiría el potencial creador de los y las estudiantes. Cada libro-álbum debe ser trabajado hasta satisfacer los detalles de sus creadores, e incluido posteriormente en la biblioteca del rincón de lecturas, donde estará a la disposición de futuras actividades de enseñanza y aprendizaje, dentro del aula y la institución.

\section{A manera de observaciones finales}

Es recomendable que la propuesta se lleve acabo, como mínimo, en dos días. Dependiendo de los diálogos base con que el docente trabaje, cada sesión duraría entre dos horas y media o tres. De acá el hecho de que las actividades, el tono de voz, los accesorios, la disposición, conformidad y preparación del rincón sean motivadores en todo momento. Cada una de las actividades de (re)creación debe funcionar como un lapso de esparcimiento, de manera que los niños y las niñas generen y conciban materialidades críticas y significativas (pintoretas, opiniones personales, rompecabezas, listados, dramatizaciones, libro-álbum, entre otros) sin presión, debido a lo extenso de las sesiones.

Asimismo, las actividades deben incorporar técnicas y recurso, tanto los propuestos, como otros considerados por el docente ejecutante, cuyo fin sea que los y las estudiantes agilicen sus procesos de enseñanza y aprendizaje productivamente, tomando en cuenta sus distintos tipos de aprendizaje, niveles de concentración, capacidades e, inclusive, incorporación efectiva y estratégica de los y las estudiantes con déficit atencional o adecuaciones curriculares.

El fin último de esta propuesta es dirigir a niños y niñas a una lectura crítica y significativa, en tanto se les brindan otras competencias (inter)textuales, a partir de escritos que parecieran lejanos y desconocidos al inicio, pero, al final, familiares y contextualizados, gracias a las técnicas electas, las cuales deben encontrarse siempre en función del reforzamiento de las inteligencias interpersonal, lingüística, kinestésica y emocional.

La productividad de la lectura radica, según esta propuesta, en que los y las estudiantes le tiendan trampas al lenguaje por medio de la literatura, implicando así una subversión y cuestionamiento de los poderes que, como lectores sujetados, habitamos y transcribimos, hegemónica y reproductivamente (principal limitante), sobre otros textos:

Como dice Claudia López, abrir un debate acerca del canon quiere decir, cuestionar una autoridad: los libros sagrados. Lejos de sacralizar autores, géneros, formas, pensamos en la importancia de no excluir y de ser lectores críticos y abiertos a todo, hasta a lo que nos ofrece resistencia. En esa idea inclusiva, por ejemplo, nos parece preocupante un canon que apuesta a "lo seguro" o a "lo fácil" y deja afuera a géneros que ofrecen más incertidumbre como, por ejemplo, la poesía y la literatura fantástica (Bajour, 2005, Sección "Abrir el juego en la selección de textos literarios", ๆ 1).

\section{Notas}

1 El abordaje metodológico en torno al estudio de los textos literarios en las aulas de secundaria en Costa Rica insiste todavía en reproducir un enfoque formalista, a pesar de las pretensiones del conocimiento previo del constructivismo y la plurisignificación de la literatura exigida por los Planes de Estudio de Español del Ministerio de Educación Pública. En el caso de la educación primaria, el ejercicio de la lectura se delimita a un nivel literal de los textos, con el cual se busca una comprobación superficial en la mayoría de los casos. Ambas dinámicas 
contraproducentes se deben en gran parte, primero, a una formación curricular del profesor, caracterizada por una deficiente apertura teórica ante el fenómeno literario; y, segundo, al sistema evaluativo contradictorio del M.E.P., pues plantea lineamientos sobre una lectura significativa, dinámica e intertextual constante junto a una evaluación formativa, pero al mismo tiempo impone una evaluación de la calidad de los aprendizajes mediante instrumentos de medición meramente sumativos, los cuales se han convertido en el propósito primordial del proceso educativo.

En esta y siguientes citas textuales, enfatizo con letra cursiva y negrita el fragmento de esta que me interesa, en relación con la idea presentada en su respectivo momento.

Esta competencia debe ser la consigna prioritaria en este momento durante la práctica docente.

El humor, como mecanismo retórico, permite la deconstrucción de la realidad hegemónica y configura nuevos modelos de lectura y vivencias cotidianas.

El M.E.P. establece que el proceso de comprensión lectora, tanto en primaria como secundaria, debe abarcar los niveles: 1) literal o explícito, en donde se pretenden reconocer detalles, ideas, secuencias o características dentro de la diégesis narrativa o textual, ello en función de la memoria; 2) de organización de la información explícita, en donde el estudiante debe organizar, analizar y sintetizar la información expresa en el texto; 3) inferencial, a medida que el estudiante conjetura (con) el texto, a partir de sus experiencias previas e intuiciones lectoras; 4) de evaluación, en tanto se emiten juicios valorativos desde un análisis objetivo y fundamentado; 5) de apreciación, según el estudiante responde subjetivamente ante el contenido o carácter estético del texto; y 6) de aplicabilidad y recreación, en donde el lector (de)construye el texto en otras dimensiones posibles.

\section{Referencias bibliográficas}

Althusser, L. (1977). Ideología y aparatos ideológicos del Estado. Freud y Lacan. Buenos Aires: Nueva Visión.

Andersen, H. (2005). Cuentos infantiles [Versión electrónica]. En L. López Nieves, Ciudad Seva, Hogar electrónico del escritor Luis López Nieves. Recuperado de Biblioteca Digital el 24 de julio del 2008 de www.ciudadseva.com/textos/cuentos/euro/andersen/hca.htm

Bajour, C. y Carranza, M. (2005). Abrir el juego en la literatura infantil y juvenil. Ponencia presentada el 27 de octubre del 2004, en De las raíces a las alas. Tucumán en tiempos de lectura, Plan Nacional de Lectura, San Miguel de Tucumán, Argentina. Recuperado de Revista Imaginaria, $\mathrm{N}^{\circ} 158$, el 24 de julio del 2008 de http://www.imaginaria.com.ar/15/8/ abrir-el-juego.htm

Barthes, R. (2003). Placer del texto y lección inaugural. Buenos Aires: Siglo XXI.

Butler, J. (2001). El género en disputa: El feminismo y la subversión de la identidad. México: Paidós.

Costa Rica, Ministerio de Educación Pública [M.E.P.]. (2000). Plan de estudio español I, II, III y IV ciclo [Versión electrónica]. San José, Costa Rica: M.E.P. Recuperado el 24 de julio del 2008 de www.mep.go.cr 
García, A. (1994). Teoría de la literatura. Madrid: Cátedra.

García, N., Campos, N., Campos, E. y Rojas, M. (1992). Conocimiento participación y cambio. Espacio en el aula. San José, Costa Rica: Editorial de la Universidad de Costa Rica.

Lozano, J. (2007). Análisis del discurso: Hacia una semiótica de la interacción textual. Madrid, España: Cátedra.
Piaget, J. (1989). La construcción de lo real en el niño. Barcelona, Editorial Crítica.

Rojas, J. (2008). El gato de sí mismo: Novela de la travestización. Manuscrito no publicado. Presentado en el curso Utopías y perversiones de las sociedades posmodernas, de la Maestría Académica en Literatura Latinoamericana, Universidad de Costa Rica, San José, Costa Rica. 